\title{
HPLC detection of synthetic dyes in residual waters from wastewater treatment using adsorption on magnetic materials
}

https://doi.org/10.21698/rjeec.2020.203

Proceedings Paper

\author{
ALINA TATARUS ${ }^{1,2}$, CLAUDIA MARIA SIMONESCU², ROXANA ELENA SCUTARIU ${ }^{1}$, \\ VASILE ION IANCU ${ }^{1}$, FLORINELA PIRVU ${ }^{1}$, DIANA PUIU ${ }^{1}$, TOMA GALAON $^{1 *}$ \\ ${ }^{1}$ National Research and Development Institute for Industrial Ecology - ECOIND, 71-73 Drumul Podu Dambovitei, \\ 060652, Bucharest, Romania \\ ${ }^{2}$ University Politehnica of Bucharest, Faculty of Applied Chemistry and Materials Science, Department of Analytical \\ Chemistry and Environmental Engineering, 1-7 Polizu, 011061, Bucharest, Romania \\ *Corresponding author (e-mail): toma.galaon@incdecoind.ro
}

\section{Abstract}

Surface water contamination by synthetic dyes generates human and wildlife adverse health effects and causes photosynthesis activity decrease due to intense sun-light absorption of these pollutants. $50 \%$ of total discharged industrial effluents contain azo dyes. Congo Red is a benzidine based anionic azo dye that is usually employed in the rubber, paper, and plastic industries. Congo Red can cause eye and skin irritation and is potentially carcinogenic. This study explores the development of a new HPLC method to detect synthetic dyes in residual waters coming from wastewater treatment technologies based on magnetic material adsorption. Cobalt ferrite $\left(\mathrm{CoFe}_{2} \mathrm{O}_{4}\right)$ and chitosan-coated cobalt ferrite $\left(\mathrm{CoFe}_{2} \mathrm{O}_{4}\right.$-Chit) prepared by a simple co-precipitation method were tested as adsorbents for Congo Red (CR). The effect of contact time, solution $\mathrm{pH}$, and initial dye concentration were studied with respect to Congo Red adsorption efficiency. The adsorption experiments were performed at $\mathrm{pH}=4.5$ and 10.8. The highest value for the removal efficiency using the magnetic material of cobalt ferrite coated with chitosan $\left(\mathrm{CoFe}_{2} \mathrm{O}_{4}\right.$-Chit) was obtained at pH 10.8.

Keywords: adsorption, HPLC, magnetic materials, synthetic dyes, wastewater treatment

\section{INTRODUCTION}

Water is a very stable compound vital for all known forms of life. Industrialization and modernization have negatively influenced clean water resources. Many substances, such as heavy metals [1], dyes, pharmaceuticals [2], surfactants, pesticides, personal care products, and others, have contaminated water resources [3]. In recent years, the use of synthetic chemical dyes in various industrial processes has increased considerably. Some areas where these chemicals are frequently used are paper and pulp manufacturing, dyeing of cloth, plastics, leather treatment, printing, etc. Industrial wastewaters containing such dyes are generally discarded as effluents. Since some of these dyes are toxic, their removal from industrial effluents is a major environmental problem [4]. It has been found that these pollutants are carcinogenic, toxic, and harmful, in addition to causing many health problems such as allergy, skin irritation, nausea, hard breathing, sweating, vomiting, high bold pressure, confusion, headache, and mutations [5].

Dyes have complex aromatic molecular structures and are generally resistant to light, temperature, and oxidizers. This characteristic feature makes the dye non-degradable and therefore causes bioaccumulation in living organisms, leading to severe diseases and disorders [6]. Discarding synthetic dyes containing effluents into surface water can cause severe problems such as increasing the chemical oxygen demand (COD), delaying the growth of microorganisms, and reducing light penetration and visibility. Besides, dyes are resistant to light and moderate oxidative agents; therefore, they cannot be completely removed by conventional biological treatment processes, such as activated sludge and anaerobic digestion [7]. Normally, dyes are water-soluble or water-dispersible organic compounds that can be absorbed into the substrate by destroying the crystal structure of the substance. Dye molecules are chemically bound to the surface and after application to material, they become part of it [8]. Dyes may be classified as anionic (acid and color reagents), cationic (basic dyes), and non-ionic (dispersion dyes) dyes. However, reactive azo dyes constitute more than $50 \%$ of 
all textile dyes used in industry and are characterized by the existence of double azonitrogen bonds [9]. There are more than 100,000 commercial dyes with over $7 \times 10^{5}$ tons of dyes produced annually and approximately $10 \%$ were discharged from textile and related industries [10].

Multiple purification methods are used for dyes removal, namely filtration, chemical coagulation and precipitation, chemical oxidation, electrochemical removal and electrocoagulation, photocatalysis, ultrasonic or biological decomposition, and adsorption. Adsorbents are the main key for adsorption where a wide range of materials was used for this purpose. Conventional adsorbents such as clay, zeolite, bentonite, and montmorillonite were highly reported due to their abundance and low cost. However, finding new materials or modifying the classical ones were used to obtain high adsorption capacity and better adsorption conditions. For example, activated carbon is highly reported in terms of dyes and organics adsorption because of its remarkable effectiveness in this field, although its cost is relatively high and limits its usage [11]. There are numerous common approaches to eliminate the dyes from water/wastewater. These technologies can be divided into three categories: physical methods such as membrane filtration processes (nano-filtration, reverse osmosis, electrodialysis), sorption techniques, ion exchange, irradiation, electrokinetic coagulation; chemical methods such as oxidative process, $\mathrm{H}_{2} \mathrm{O}_{2}+\mathrm{Fe}$ (II) salts (Fenton's reagent), ozonation, photochemical, electrochemical destruction; and biological methods such as decolorization by white-rot fungi, adsorption by living/dead microbial biomass, anaerobic textile-dye bioremediation systems and other microbial [12]. An adsorbent is a porous insoluble sponge-like substance with the ability to capture and trap adsorbate particles onto itself. This is the most crucial element of the adsorption process. The one issue frequently related to the adsorption technique is the cost of the adsorbent utilized. Adsorption is an exceptional dye removal technique as it does not require any additional special equipment and is easy to conduct. Adsorption is different, depending on solutions and membrane member properties, but is facilitated mainly in the hydrophobic region of membrane materials, due to hydrophobic interactions [13]. A good adsorbent should be able to function in varying dye concentrations, a wide range of $\mathrm{pH}$ as well as temperature [14]. Adsorption is one of the effective and economical methods for treating contaminants such as synthetic dyes, for example, Congo Red (CR). This involves the use of various materials (adsorbents) to remove contaminants from aqueous solutions. Congo Red is an azo dye most often used in the textile industry. It is believed to be the first dye with the ability to dye cotton, is very soluble in water, and is frequently used in the textile, plastic, and industrial industries. Congo Red becomes a contaminant when it is discharged into water bodies in the form of industrial effluent without being properly treated and therefore turns from a good product into a pest. It is difficult to degrade biologically due to its stable structure, which endangers the environment [15]. Water matrices have complex content from a physical and chemical point of view, and this makes it difficult to create an adequate analytical method [16]. The main innovation of the HPLC method is the possibility to analyze a wide variety of dyes (direct dispersed, reactive, acid, and basic dyes) with a single chromatographic method. Also, the inclusion of both Diode Array Detector (DAD) and MS analyzes allows a precise and sensitive analysis of the dyes. Other techniques used routinely in most laboratories are UV/VIS micro spectrometry (MSP) and Fourier-transform infrared spectrometry (FTIR). Many laboratories use additional techniques, such as Raman spectrometry, thin layer chromatography, chemical, and melting tests [17].

The present paper was focused on the development of a new HPLC-DAD method for the detection of Congo Red dye from water samples. The HPLC-DAD method was applied to test the removal efficiency of Congo Red from synthetic aqueous solutions using adsorption on magnetic materials such as Cobalt ferrite $\left(\mathrm{CoFe}_{2} \mathrm{O}_{4}\right)$ and chitosan-coated cobalt ferrite $\left(\mathrm{CoFe}_{2} \mathrm{O}_{4}\right.$-Chit). Similar magnetic material adsorption experiments regarding Congo Red and other dyes will be extended in another study on real wastewater sample matrices. 


\section{EXPERIMENTAL PART}

\section{Chemicals and working standard solution}

Acetonitrile, methanol, and ammonium acetate for liquid chromatographic analysis (HPLC) were purchased from Merck. $\mathrm{C}_{32} \mathrm{H}_{22} \mathrm{~N}_{6} \mathrm{Na}_{2} \mathrm{O}_{6} \mathrm{~S}_{2}$ was used as the source for the Congo Red stock solution. $25 \mathrm{mg}$ of $99 \% \quad \mathrm{C}_{32} \mathrm{H}_{22} \mathrm{~N}_{6} \mathrm{Na}_{2} \mathrm{O}_{6} \mathrm{~S}_{2}$ (Sigma Aldrich) was dissolved in $25 \mathrm{~mL}$ of methanol to prepare $1000 \mathrm{mg} / \mathrm{L}$ of Congo Red stock solution. Samples of different concentrations of Congo Red were prepared from this stock solution by appropriate dilutions (Fig. 1).

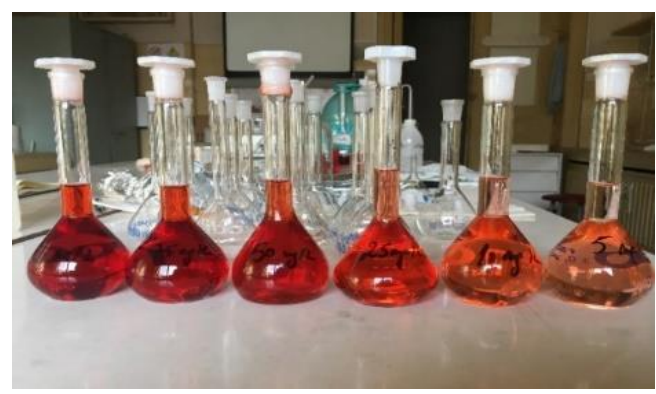

Fig. 1. Congo Red samples of different concentrations

The raw materials such as $\mathrm{Fe}\left(\mathrm{NO}_{3}\right)_{3} \cdot 9 \mathrm{H}_{2} \mathrm{O} 96 \%$, $\mathrm{Co}\left(\mathrm{NO}_{3}\right)_{2} \cdot 6 \mathrm{H}_{2} \mathrm{O}$, chitosan, glacial acetic acid (analytical grade, Sigma Aldrich) were used in

\section{Equipment and chromatographic method}

Congo Red analysis was performed on an Agilent 1200 series HPLC system equipped with: semipermeable membrane degasser, quaternary pump, autosampler with variable injection volume $(0.1-100 \mu \mathrm{l})$, thermostatted column compartment, and a Diode Array Detector (DAD) with the ability to record simultaneously UV-VIS spectra (190-900 nm) and up to 8 discrete wavelengths in this range. Agilent ChemStation software was used for data acquisition, processing, and reporting. The optimum mobile phase composition was 100 $\mathrm{mM}$ Ammonium Acetate in water brought to pH 5.0 and Acetonitrile in the ratio 30/70 (v/v). All chromatographic runs were carried out on the synthesis of magnetic materials. The solutions $\mathrm{pH}$ was changed with $\mathrm{HCl} 35 \%$ suprapure and $\mathrm{NH}_{4} \mathrm{OH} 25 \%$ (Merck origin).

an Acclaim Surfactant Plus column (150 x 3.0 $\mathrm{mm}, 3.0 \mu \mathrm{m})$ from Thermo Scientific. The column was kept at $30^{\circ} \mathrm{C}$. Experiments were performed in isocratic elution conditions at a flow rate of $0.5 \mathrm{~mL} / \mathrm{min}$. Injection volume was $10 \mu \mathrm{L}$ and the chromatogram run-time was only 9 minutes (Congo Red retention time approx. $7.6 \mathrm{~min}$ ). Detection of the target compound was performed at the absorption maximum of 506 $\mathrm{nm}$ which was observed in the UV-Vis spectrum obtained by HPLC-DAD. Figure 2 shows the structural formula of Congo Red, while in Figure 3 it is presented its UV-Vis spectrum obtained by HPLC-DAD.

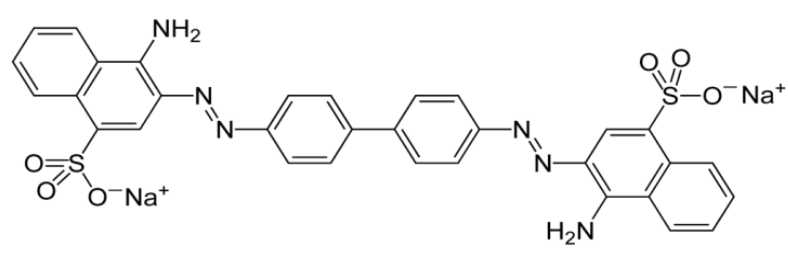

Fig. 2. Structural formula of Congo Red $\left(\mathrm{C}_{32} \mathrm{H}_{22} \mathrm{~N}_{6} \mathrm{Na}_{2} \mathrm{O}_{6} \mathrm{~S}_{2}\right)$ 


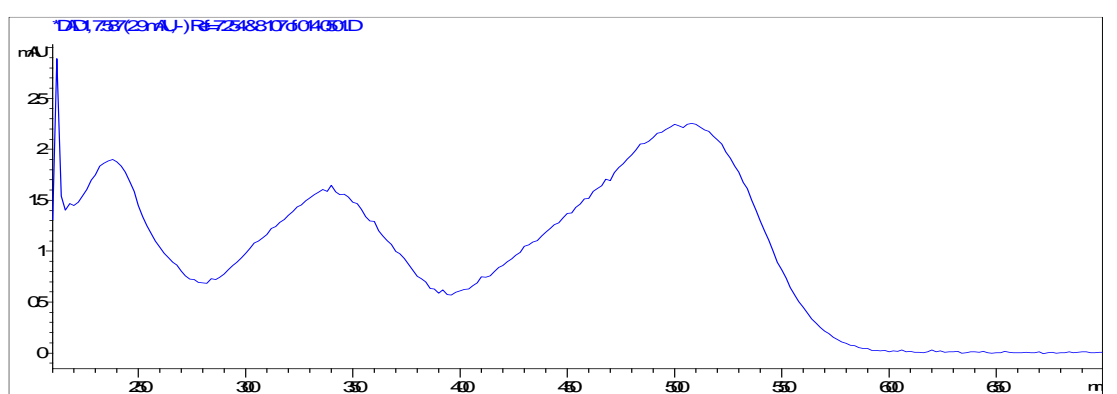

Fig. 3. UV-VIS absorption spectra of Congo Red obtained by HPLC-DAD

The effects of operating conditions on the CR removal process were determined in batch experiments using a GFL 3015 orbital shaker at $150 \mathrm{rpm}$ (rotation per minute). All the experiments were carried out at room temperature. The dye solution's $\mathrm{pH}$ was established with an Agilent 3200 laboratory pHmeter. The influence of CR solution's $\mathrm{pH}$ was established in experiments using a solution of $102.81 \mathrm{mg} \mathrm{CR} / \mathrm{L}$ (experimentally determined). The volume of $\mathrm{CR}$ solution used in the experiments is $25 \mathrm{~mL}$, and the amount of adsorbent was $0.01 \mathrm{~g}$. The experiments were performed at room temperature over 6 hours to

$$
R=\frac{c_{0}-c_{\mathrm{t}}}{c_{0}} \times 100 \%
$$

where $\mathrm{R}(\%)$ is the $\mathrm{CR}$ removal efficiency, $\mathrm{C}_{0}$ $(\mathrm{mg} / \mathrm{L})$ is the initial concentration of $\mathrm{CR}$, and $\mathrm{C}_{t}$

\section{RESULTS AND DISCUSSION}

The cobalt ferrite $\left(\mathrm{CoFe}_{2} \mathrm{O}_{4}\right)$ and chitosancoated cobalt ferrite $\left(\mathrm{CoFe}_{2} \mathrm{O}_{4}\right.$-Chit $)$ were prepared by the co-precipitation method. The synthesis protocol and characterization of both materials were described in the previous publication [18].

Considering the significant water solubility and polarity of Congo Red, which are mainly given by its sulfonic groups, it was decided to separate this compound using a chromatographic column dedicated to surfactant separation (Acclaim Surfactant Plus). The reason for this column choice was the structural similarity between surfactants and some synthetic dyes when considering the highly ionized polar groups in their molecules (sulfonic group, quaternary ammonium, etc.). To obtain a rapid and sensitive HPLC method, multiple optimization tests were performed using different injection volumes $(2 \mu \mathrm{L}, 10 \mu \mathrm{L})$, different values of the mobile phase flow-rate reach equilibrium. Tests were performed in the range of $\mathrm{pH} 2.22-10.8$, the $\mathrm{pH}$ of the solution was changed using $\mathrm{HCl}$ and $\mathrm{NH}_{4} \mathrm{OH}$ solutions of various concentrations. The equilibrium time was determined from tests performed in the time range of 5-360 $\mathrm{min}$. The influence of initial $\mathrm{CR}$ concentration on the adsorption efficiency using $\mathrm{CoFe}_{2} \mathrm{O}_{4}$ and $\mathrm{CoFe}_{2} \mathrm{O}_{4}$-Chit was achieved from experiments conducted by varying the concentration in the range of 4.98$102.81 \mathrm{mg} \mathrm{CR} / \mathrm{L}$.

The $\mathrm{CR}$ removal efficiency (R, \%) was calculated using the following equation:

$(\mathrm{mg} / \mathrm{L})$ is the concentration of $\mathrm{CR}$ at various contact times/different $\mathrm{pH}$ values.

(0.5 mL/min, $0.6 \mathrm{~mL} / \mathrm{min})$. Also, for the elution under an isocratic regime, different compositions of the mobile phase were tested with variable proportions between the aqueous and organic solvent (50/50, 30/70, 25/75, 20/80). The optimum composition for the mobile phase was $30 \%$ aqueous phase $(100 \mathrm{mM}$ ammonium acetate, $\mathrm{pH} 5$ ) and $70 \%$ organic solvent (Acetonitrile), which resulted in narrow and high symmetry Congo Red peak. The detection wavelength was also optimized considering maximum sensitivity. Accordingly, $506 \mathrm{~nm}$ was chosen as Congo Red detection wavelength in the Visible domain. Selected wavelength allowed quantitation of Congo Red down to $0.02 \mathrm{mg} / \mathrm{L}(20 \mu \mathrm{g} / \mathrm{L})$ with a $\mathrm{S} / \mathrm{N}$ ratio of approx. 10.

Final optimized LC parameters (surfactant column, $10 \mu \mathrm{L}$ injection volume, $0.5 \mathrm{~mL} / \mathrm{min}$ flow-rate, 30/70 mobile phase composition, 506 $\mathrm{nm}$ detection wavelengths) allowed for rapid 
and sensitive detection of Congo Red which presented increased peak efficiency and the reduced retention time (7.5 min). Method calibration curve was obtained using Congo Red aqueous solutions of: $0.1 \mathrm{mg} / \mathrm{L}, 0.2 \mathrm{mg} / \mathrm{L}$, $0.5 \mathrm{mg} / \mathrm{L}, 1 \mathrm{mg} / \mathrm{L}, 2.5 \mathrm{mg} / \mathrm{L}, 5 \mathrm{mg} / \mathrm{L}$ and 10
mg/L (Fig. 4). Expected levels of Congo Red in spiked water samples (laboratory-controlled) before and after adsorption (removal) on magnetic materials did not require a lower calibration level.

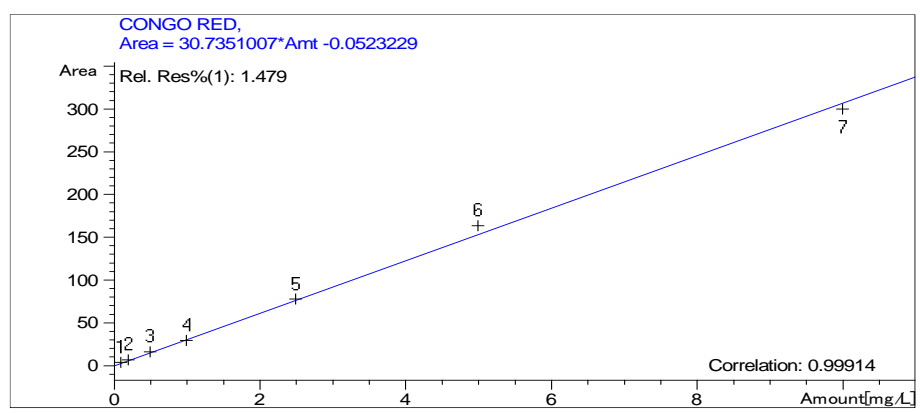

Fig. 4. HPLC-DAD calibration curve of Congo Red

The influence of the process control parameters such as contact time, dye solution $\mathrm{pH}$, and initial CR concentration on removal efficiency was examined. The results regarding the influence of $\mathrm{CR}$ solutions $\mathrm{pH}$ on removal efficiency is depicted in Figure 5.

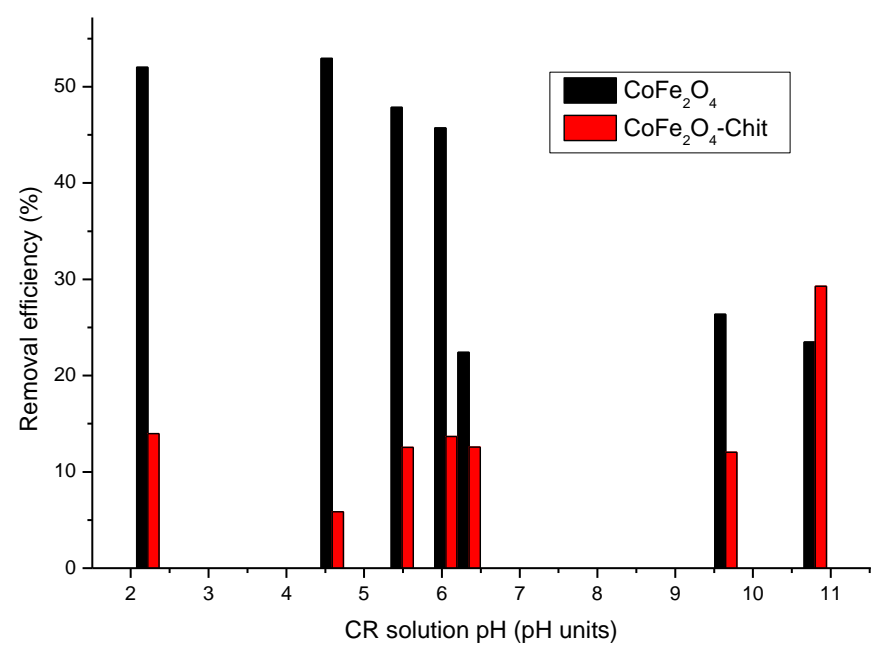

Fig. 5. The effect of CR solution's $\mathrm{pH}$ on removal efficiency

From the examination of the results presented in Figure 5, it can be observed that magnetic materials tested are characterized by different adsorption behavior. A decrease in removal efficiency with the increase of $\mathrm{CR}$ solution $\mathrm{pH}$ was noticed in the case of $\mathrm{CoFe}_{2} \mathrm{O}_{4}$. This may be due to the fact that at lower $\mathrm{pH}$, the $\mathrm{CR}$ has a cationic form, and thus there can be a strong electrostatic attraction between the positively charged CR molecules and negatively charged $\mathrm{CoFe}_{2} \mathrm{O}_{4}$ surface. This has as result the higher removal efficiency at lower $\mathrm{pH}$. At higher $\mathrm{pH}$, the removal efficiency is reduced due to the strong electrostatic repulsion between the negative surface of $\mathrm{CoFe}_{2} \mathrm{O}_{4}$ and the anionic form of CR molecules that can be found in the basic medium. The higher removal efficiency was observed at a $\mathrm{pH}$ of around 4.5 for $\mathrm{CoFe}_{2} \mathrm{O}_{4}$. A different behavior was found in the case of $\mathrm{CoFe}_{2} \mathrm{O}_{4}$-Chit. At lower $\mathrm{pH}$, there is a high concentration of protons that protonate the amine $\left(-\mathrm{NH}_{2}\right)$ and hydroxyl groups $(-\mathrm{OH})$ from the chitosan structure. These protonated sites will interact by electrostatic forces with negatively charged sulfonic functional groups of Congo Red. However, there can occur repulsive forces with protonated functional groups of Congo Red (Fig. 6). 


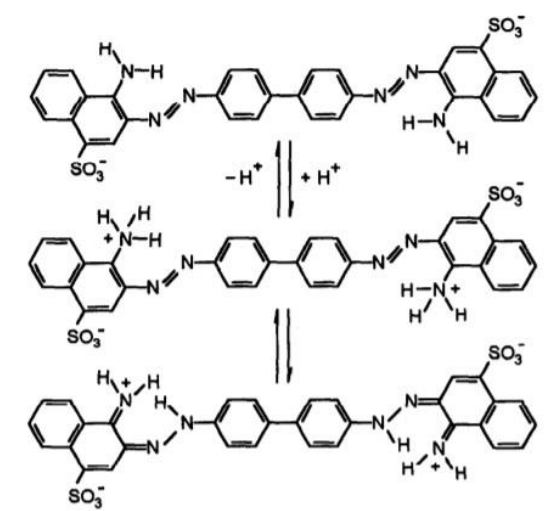

Fig. 6. Protonation and tautomeric equilibrium of the Congo red in acidic solution [19]

At higher $\mathrm{pH}$, the protonation of the $\mathrm{CR}$ is reduced and the sulfonate groups can interact electrostatically with the positive functional groups from the surface of chitosan. Also, hydrogen bonding and van der Waals forces can occur with effect on the removal efficiency in a neutral or slightly acid medium. The higher value of removal efficiency has been registered at $\mathrm{pH}$ equal with 10.8. Similar trends regarding the effect of the $\mathrm{CR}$ solutions $\mathrm{pH}$ are presented in the literature data [20]. Another conclusion that can be drawn from these results is that the $\mathrm{CoFe}_{2} \mathrm{O}_{4}$ has a higher CR removal efficiency than $\mathrm{CoFe}_{2} \mathrm{O}_{4}$-Chit. This can be explained by the fact that $\mathrm{CoFe}_{2} \mathrm{O}_{4}$-Chit has been prepared as macroparticles while $\mathrm{CoFe}_{2} \mathrm{O}_{4}$ was obtained as nanoparticles (Fig. 7). Consequently, $\mathrm{CoFe}_{2} \mathrm{O}_{4}$ Chit has a lower specific surface area, adsorption capacity, and efficiency than $\mathrm{CoFe}_{2} \mathrm{O}_{4}$.

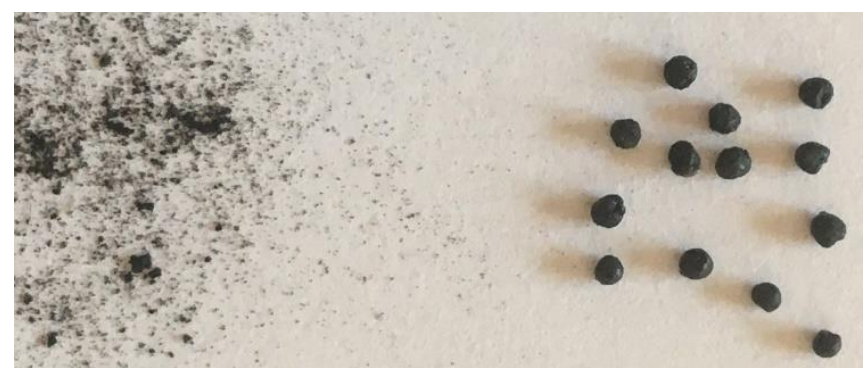

Fig. 7. The image of $\mathrm{CoFe}_{2} \mathrm{O}_{4}$ particles (left) and $\mathrm{CoFe}_{2} \mathrm{O}_{4}$-Chit particles (right)

The variation of removal efficiency with the contact time is displayed in Figure 8. The experiments have been performed at $\mathrm{pH}=4.5$ and 10.8 .

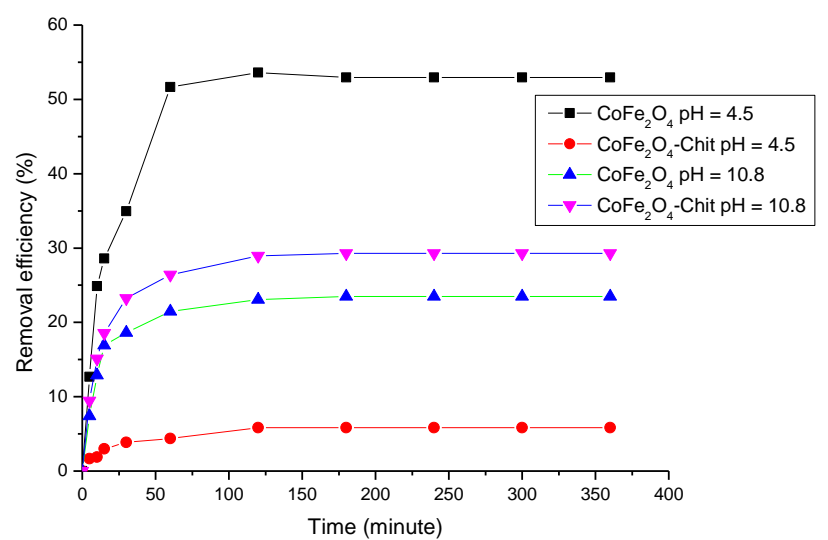

Fig. 8. The effect of contact time on the removal efficiency of $\mathrm{CoFe}_{2} \mathrm{O}_{4}$ and $\mathrm{CoFe}_{2} \mathrm{O}_{4}-\mathrm{Chit}$

According to the results from Figure 8, it can be concluded that the time to reach the equilibrium is 180 minutes for both materials tested. The rate of the CR removal process is higher in the 
first 30 minutes due to the numerous free active sites on the surface of the adsorbent. After this period the removal rate increases slowly as a consequence of the saturation of active sites. The influence of the CR concentration in the initial solutions/wastewater was analyzed in experiments with $\mathrm{CR}$ solutions with a concentration in the range $4.98-102.91 \mathrm{mg} / \mathrm{L}$ at 240 minutes contact time. The results are summarized in Figure 9.

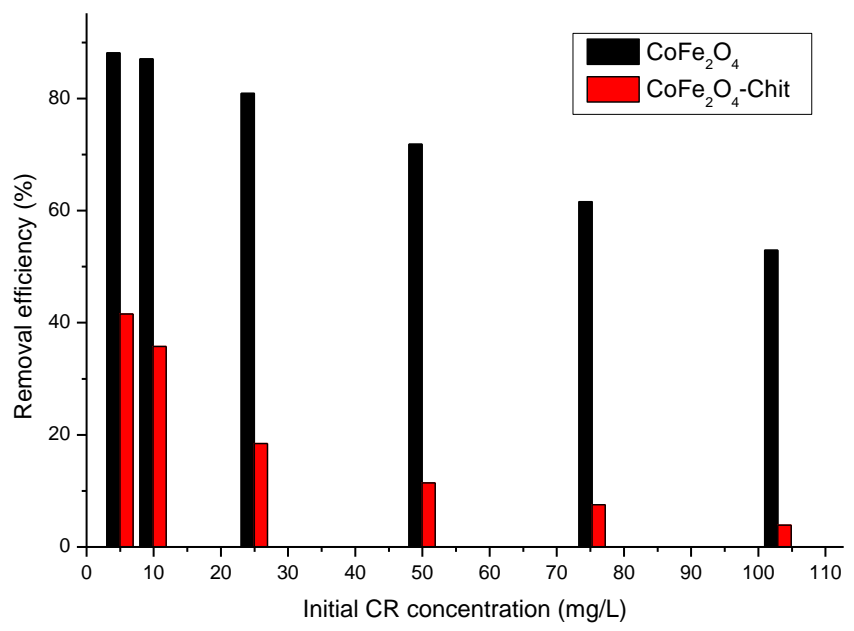

Fig. 9. The effect of initial CR concentration on removal efficiency of $\mathrm{CoFe}_{2} \mathrm{O}_{4}$ and $\mathrm{CoFe}_{2} \mathrm{O}_{4}-\mathrm{Chit}$

Figure 9 shows that the removal efficiency decreases from 88.15 to $52.91 \%$ as the initial Congo Red concentration increases from 4.98 to $102.91 \mathrm{mg} / \mathrm{L}$ for adsorption onto $\mathrm{CoFe}_{2} \mathrm{O}_{4}$. A decrease from 41.57 to $3.91 \%$ was observed for adsorption onto $\mathrm{CoFe}_{2} \mathrm{O}_{4}$-Chit. This can be

\section{CONCLUSIONS}

The present study was developed a highly sensitive and rapid HPLC-DAD method for the detection of Congo Red dye from spiked water samples. Chromatographic separation was achieved in 9 minutes. All HPLC method parameters (nature and composition of the mobile phase, flow-rate, injection volume, detector wavelength, and column temperature) were optimized for the rapid separation and sensitive detection of Congo Red to determine this synthetic dye at concentration levels down to parts per billion $(\mu \mathrm{g} / \mathrm{L})$ from aqueous solutions. Due to several UV-Vis chromophores and conjugated aromatic rings present in Congo Red molecule, highly sensitive detection of this analyte was achieved at $506 \mathrm{~nm}$ with an instrumental quantitation limit (HPLC-DAD) of $0.02 \mathrm{mg} / \mathrm{L}(20 \mu \mathrm{g} / \mathrm{L})$. Nonetheless, a 5 time's higher concentration level was employed as the lowest level for the Congo Red calibration curve of $(0.1-10 \mathrm{mg} / \mathrm{L})$.

Cobalt ferrite and chitosan-coated cobalt ferrite explained based on the ratio of the available active sites of magnetic materials/adsorbents to the initial number of moles of Congo Red is large at low initial concentration. According to this, the fractional adsorption does not depend on initial concentration [21].

were employed for the adsorption removal of Congo Red dye from synthetic water samples. In the case of cobalt ferrite, the maximum retention efficiency (R) was recorded at a $\mathrm{pH}$ value of $4.5 \mathrm{As}$ the $\mathrm{pH}$ value increases, there is a decrease in retention efficiency. In the case of cobalt ferrite coated with chitosan, it was found that the maximum retention value was recorded at a $\mathrm{pH}$ value of 10.8. As the $\mathrm{pH}$ increases, the amount of Congo Red retained per gram of cobalt ferrite coated with chitosan increases. With increasing $\mathrm{pH}$, the electrostatic attraction interactions between the negatively charged surface of the chitosan-coated cobalt ferrite and the Congo Red anionic molecules also increase. As a result of low pH values, the adsorption of Congo Red, which is an anionic dye, is reduced and increases with increasing $\mathrm{pH}$. As a result, experiments to establish the equilibrium time were performed at two $\mathrm{pH}$ values (4.5 and 10.8 ), resulting in a decrease in values from 41.57 to $3.91 \%$ for adsorption on $\mathrm{CoFe}_{2} \mathrm{O}_{4}$-Chit. 


\section{ACKNOWLEDGEMENTS}

The authors acknowledge the financial support offered by The National Research Program

\section{REFERENCES}

[1] KIM, L., VASILE, G., STANESCU, B., DINU, C., ENE, C., Rev. Chim., 67, no. 8, 2016, p. 1141.

[2] IANCU, V., RADU, G. L., PETRE, J., GALAON, T., SCUTARIU, R. E., PIRVU, F., PAUN, I., SERBAN, G., The Environment and the Industry, 2019, p. 67, https://doi.org 10.21698/simi.2018.fp48.

[3] SIYAL, A. A., SHAMSUDDIN, M. R., KHAN, M. I., RABAT, N. E., ZULFIQAR, M., MAN, Z., SIAME, J., AZIZLI, K. A., J. Environ. Manage., 224, 2018, p. 327, https://doi.org/10.1016/j.jenvman.2018.07.046.

[4] MADRAKIAN, T., AFKHAMI, A., \& AHMADI, M., Spectrochim. Acta A Mol. Biomol. Spectrosc., 99, 2012, p. 102, https://doi.org/10.1016/j.saa.2012.09.025.

[5] KADHOM, M., ALBAYATI, N., ALALWAN, H., AL-FURAIJI, M., Sustain. Chem. Pharm., 16, 2020, https://doi.org/10.1016/j.scp.2020.100259.

[6] BANERJEE, S., CHATTOPADHYAYA, M. C., Arab. J. Chem., 10, 2017, p. S1629, https://doi.org/10.1016/j.arabjc.2013.06.005.

[7] SRILAKSHMI, C., SARAF, R., Microporous and Mesoporous Mater., 219, 2016, p. 134, https://doi.org/10.1016/j.micromeso.2015.08.00 3.

[8] NGULUBE, T., GUMBO, J. R., MASINDI, V., MAITY, A., J. Environ. Manag., 191, 2017, p. https://doi.org/10.1016/j.jenvman.2016.12.031. [9] ALVER, E., METIN, A. U., Chem. Eng. J., 200-202, 2012, p. 59, https://doi.org/10.1016/j.cej.2012.06.038.

[10] PARVIN, S., BISWAS, B. K., RAHMAN, A., RAHMAN, H., ANIK, S., UDDIN, R., Chemosphere, 236, 2019, 124326, https://doi.org/10.1016/j.chemosphere.2019.07. 057.
"Nucleu" through contract no 20N/2019, Project code PN 19040101.

[11] KADHOM, M., ALBAYATI, N., ALALWAN, H., AL-FURAIJI, M., Sustain. Chem. Pharm., 16, 2020, https://doi.org/10.1016/j.scp.2020.100259.

[12] HASANPOUR, M., HATAMI, M., J. Mol. Liq., 309, 2020, https://doi.org/10.1016/j.molliq.2020.113094.

[13] SCUTARIU, R. E., IANCU, V. I., NECHIFOR, G., RADU, G. L., SIMION, M., NICULESCU, M., International Symposium The Environment and the Industry, 2018, p. 392, https://doi.org 10.21698/simi.2018.fp48.

[14] KATHERESAN, V., KANSEDO, J., LAU, S. Y., J. Environ. Chem. Eng., 6, no. 4, 2018, p. 4676,

https://doi.org/10.1016/j.jece.2018.06.060.

[15] OLUSEGUN, S. J., MOHALLEM, N. D. S., Environ. Pollut., 260, 2020, https://doi.org/10.1016/j.envpol.2020.114019.

[16] PIRVU, F., IANCU, V. I, NICULESCU, M., LEHR, C. B, PASCU, L. F, GALAON, T., Rev. Chim. 71, no. 1, 2020, p. 390, https://doi.org/10.37358/RC.20.6.8205.

[17] SCHOTMAN, T. G., XU, X., RODEWIJK, N., WEERD, J., Forensic Sci. Int., 278, 2017, p. 338, https://doi.org/10.1016/j.forsciint.2017.07.026.

[18] SIMONESCU, C. M., TATARUS, A., CULITA, D. C., STANICA, N., GALAON, T., IONESCU I. A., Rev. Chim., in press, 2020.

[19] PIGORSCH, E., ELHADDAO, A., TURRELL, S., Spectrochim. Acta, 50, no. 12, 1994, p. 2145, https://doi.org/10.1016/05848539(94)00151-0.

[20] ZAHIR, A., ASLAM, Z., KAMAL, M. S., AHMAD, W., ABBAS, A., SHAWABKEH, R. A., J. Molec. Liq., 244, 2017, p. 211, https://doi.org/10.1016/j.molliq.2017.09.006.

[21] DEBNATH P., MONDAL, N. K., Environ. Nanotechnol. Monit. Manag., 14, 2020, https://doi.org/10.1016/j.enmm.2020.100320. 